OPEN ACCESS

Edited by:

Shuhao Huo,

Jiangsu University, China

Reviewed by:

Abd El-Fatah Abomohra,

Chengdu University, China

Xupeng Cao,

Dalian Institute of Chemical Physics, Chinese Academy of Sciences (CAS),

China

*Correspondence:

Yun $\mathrm{Li}$

sxsd/w/@ouc.edu.cn

Specialty section:

This article was submitted to

Marine Fisheries, Aquaculture

and Living Resources,

a section of the journal

Frontiers in Marine Science

Received: 07 December 2021

Accepted: 27 December 2021

Published: 14 January 2022

Citation:

Cao Z, Shen $X$, Wang $X$, Zhu $B$,

Pan K and Li Y (2022) Effect

of Nitrogen Concentration on

the Alkalophilic Microalga

Nitzschia sp. NW129-a Promising

Feedstock for the Integrated

Production of Lipids and Fucoxanthin

in Biorefinery.

Front. Mar. Sci. 8:830590.

doi: 10.3389/fmars.2021.830590

\section{Effect of Nitrogen Concentration on the Alkalophilic Microalga Nitzschia sp. NW129-a Promising Feedstock for the Integrated Production of Lipids and Fucoxanthin in Biorefinery}

\author{
Zihao Cao', Xiaotong Shen', Xujing Wang ${ }^{1}$, Baohua Zhu', Kehou Pan ${ }^{1,2}$ and Yun Li ${ }^{1 *}$ \\ ${ }^{1}$ The Key Laboratory of Mariculture (Ministry of Education), Ocean University of China, Qingdao, China, ${ }^{2}$ Function \\ Laboratory for Marine Fisheries Science and Food Production Processes, Qingdao National Laboratory for Marine Science \\ and Technology, Qingdao, China
}

Microalgae are considered promising resources for producing a variety of high-valueadded products, especially for lipids and pigments. Alkalophilic microalgae have more advantages than other microalgae when cultured outdoors on a large scale. The present study investigated the comprehensive effects of different nitrogen concentrations on fucoxanthin $(F x)$, lipids accumulation and the fatty acid profile of the alkaliphilic microalgae Nitzschia sp. NW129 to evaluate the potential for simultaneous production of Fx and biofuels. Fx and Lipids amassed in a coordinated growth-dependent manner in response to various concentrations, reaching $18.18 \mathrm{mg} \mathrm{g}^{-1}$ and $40.67 \%$ dry weight (DW), respectively. The biomass of Nitzschia sp. NW129 was $0.58 \pm 0.02 \mathrm{~g} \mathrm{~L}^{-1}$ in the medium at the concentration of $117.65 \mathrm{mM}$. The highest productivities of FX (1.44 $\mathrm{mg} \mathrm{L}^{-1} \mathrm{~d}^{-1}$ ) and lipid (19.95 $\pm 1.29 \mathrm{mg} \mathrm{L}^{-1} \mathrm{~d}^{-1}$ ) were obtained concurrently at this concentration. Furthermore, the fatty acid methyl esters revealed excellent biofuel properties with an appropriate value of the degree unsaturation (49.97), cetane number (62.72), and cold filter plugging point (2.37), which met the European standards for biofuel production (EN14214). These results provided a reliable strategy for further industrialization and comprehensive production of biofuel and Fx by using the alkaliphilic microalgal Nitzschia sp. NW129.

Keywords: alkaliphilic microalgae, biodiesel, fucoxanthin, lipids, nitrogen concentration, Nitzschia sp., simultaneous production

\section{INTRODUCTION}

It was reported that microalgae contributed $20 \%$ of global primary productivity (Malviya et al., 2016). Microalgae not only play a critical ecological role but also are capable of synthesizing a variety of chemicals with high commercial value, such as pigments, unsaturated fatty acids and microalgal polysaccharides and so on (Wang et al., 2018a). As one of the prospects for the third-generation biofuels, the microalgae have faster growth rates and higher productivity than oil-producing terrestrial plants by directing more energy to growth and propagation processes (Gomez-Loredo et al., 2016). Previous studies also demonstrated that microalgal biofuel was technically feasible 
(Zeng et al., 2011; Bondioli et al., 2012). Moreover, microalgae, as potential sources of fucoxanthin $(\mathrm{Fx})$, are capable of replacing macroalgae due to the advantages of high content (2.24-59.20 mg $\mathrm{g}^{-1}$ ) and manual control in the bioreactor (Xia et al., 2013; Mohamadnia et al., 2020). Fx is a carotenoid involved in photosynthesis, accounting for more than $10 \%$ of the total carotenoids in nature (Zarekarizi et al., 2019). In recent years, Fx attracted increasing attention due to its nutraceutical effects on human health such as antioxidant, anti-obesity and anti-tumor (Riccioni, 2012; Tanaka et al., 2012; Zeng et al., 2018). It has been proved to be safe for animals, including humans and hence can be used as ingredients in food industry and medical purposes, as well as an animal feed additive (Sathasivam and Ki, 2018; Mohamadnia et al., 2020).

Taking account of the commercial value of biofuel and Fx, it is of great significance to study their integrated production from microalgae. The integrated production of pigments with algal lipids has emerged as an economic strategy worth looking forward to Campenni' et al. (2013), such as simultaneous production of astaxanthin and triacylglycerol by Chlorella zofingiensis, docosahexaenoic acid and Fx by Isochrysis and so on (Liu et al., 2016; Sun et al., 2019). Previous studies showed that manipulating nitrogen concentrations was an effective way to promote the accumulation of lipid and Fx. Nitrogen stress can induce the increase of lipid content in microalgae, while Fx was the opposite (Gao et al., 2017; Yang et al., 2017; Lai et al., 2019). The response of lipids to adverse growth conditions also inhibited the growth of algal cells, resulting in constant or even reduced productivity, which was not economically feasible (Griffiths et al., 2012; Guo et al., 2021). Furthermore, nitrogen concentration can also markedly affect the fatty acid composition (Sahin et al., 2019). It determines the quality of biofuel such as combustion efficiency, cold-flow properties and viscosity (Cui et al., 2020; Andeden et al., 2021), which is rarely considered in current studies.

However, the industrialization of microalgae culture in largescale outdoor open-ponds still faces difficulties such as low productivity, contamination by invasive species, continuous supply of inorganic carbon and inefficient harvesting (Wensel et al., 2014). An effective way to reduce the cost of $\mathrm{CO}_{2}$ supply is to culture microalgae in an extremely high $\mathrm{pH}$ medium $(\mathrm{pH}>10)$ that is capable of capturing more $\mathrm{CO}_{2}$ for microalgae growth by direct reaction of $\mathrm{CO}_{2}$ with $\mathrm{OH}^{-}$in the liquid boundary layer around gas bubbles (Santos et al., 2013; Kuo et al., 2017). The $\mathrm{CO}_{2}$ utilization efficiency of Chlorella sp. AT1 cultured in $\mathrm{pH}$ 11 medium was reported to enhance several times (Kuo et al., 2017). The higher $\mathrm{pH}$ culture media would also effectively limit microbial contamination (Peng et al., 2015). Thus, compared with other microalgae, alkalophilic microalgae that have the ability to survive and thrive at extremely high $\mathrm{pH}(\mathrm{pH}>10)$ (Qu and Miao, 2021) are more appropriate for outdoor largescale culture. In commercial production, the successful use of high $\mathrm{pH}$ growth conditions for the cultivation of Spirulina. also proves the above view (Vadlamani et al., 2017). Previous studies on alkaliphilic microalgae focused on lipid production, and to our best knowledge, there have been no efforts to produce Fx and lipids simultaneously using alkalophilic microalgae. In this study, an alkalophilic microalgae Nitzschia sp. NW129, rich in lipid and Fx, was used as material. Its additional characteristic was attributed to rapid settlement, which was conducive to reducing the collection cost. The effects of different nitrogen concentrations on lipid and Fx productivities and fatty acid composition of the alkalophilic microalga Nitzschia sp. NW129 were comprehensively analyzed. The favorable performance at appropriate nitrogen concentration suggested its potential as a feedstock for the co-production of Fx and biofuel in biorefinery.

\section{MATERIALS AND METHODS}

\section{Microalgal Strain and Growth Conditions}

An oleaginous and high Fx content alkalophilic microalga isolated from Hamatai Lake (Latitude $=39^{\circ} 06^{\prime} \mathrm{N}$ and Longitude $=108^{\circ} 02^{\prime} \mathrm{E}$ ) in Mongolia, China, was identified and named Nitzschia sp. NW129 (Wang et al., 2019). The strain was preserved in the Laboratory of Applied Microalgae Biology, Ocean University of China. The Nitzschia sp. NW129 was precultured in $500 \mathrm{~mL}$ Erlenmeyer flasks placed in an Oscillating incubator at $28 \pm 1^{\circ} \mathrm{C}$ and under $100 \mu \mathrm{mol}$ photons $\mathrm{m}^{-2} \mathrm{~s}^{-1}$, following a 12:12-h light/dark photoperiod. The Zarrouk medium was used, with modifications as follows: $\mathrm{NaHCO}_{3}, 3.78 \mathrm{~g} \mathrm{~L}^{-1} ; \mathrm{Na}_{2} \mathrm{CO}_{3} 16.43 \mathrm{~g} \mathrm{~L}^{-1} ; \mathrm{NaNO}_{3} 2.5 \mathrm{~g} \mathrm{~L}^{-1}$; $\mathrm{K}_{2} \mathrm{HPO}_{4} 0.5 \mathrm{~g} \mathrm{~L}^{-1} ; \mathrm{NaCl} 1.0 \mathrm{~g} \mathrm{~L}^{-1} ; \mathrm{K}_{2} \mathrm{SO}_{4} 1.0 \mathrm{~g} \mathrm{~L}^{-1} ; \mathrm{CaCl}_{2}$ $0.08 \mathrm{~g} \mathrm{~L}^{-1} ; \mathrm{MgSO}_{4} \cdot 7 \mathrm{H}_{2} \mathrm{O} 0.2 \mathrm{~g} \mathrm{~L}^{-1} ; \mathrm{FeSO}_{4} \cdot 7 \mathrm{H}_{2} \mathrm{O} 0.01 \mathrm{~g} \mathrm{~L}^{-1}$; $\mathrm{Na}_{2}$ EDTA $0.08 \mathrm{~g} \mathrm{~L}^{-1} ; \mathrm{A}_{5} 1.0 \mathrm{ml}$. $\mathrm{A}_{5}$ consisted of the following salts, in $\mathrm{g} \mathrm{L}^{-1}: \mathrm{H}_{3} \mathrm{BO}_{3}, 5.72 ; \mathrm{MnCl}_{2} \cdot 4 \mathrm{H}_{2} \mathrm{O}, 3.60 ; \mathrm{ZnSO}_{4} \cdot 7 \mathrm{H}_{2} 0$, $0.44, \mathrm{CuSO}_{4} \cdot 5 \mathrm{H}_{2} \mathrm{O}, 0.16,\left(\mathrm{NH}_{4}\right) 6 \mathrm{Mo}_{7} \mathrm{O}_{24}$ 0.04. The $\mathrm{pH}$ of the medium was initially 10.5 and increased with the extension of cultivation time.

Late-logarithmic growth phase cells were collected by centrifuging at 4,500 $\times \mathrm{g}$ for $8 \mathrm{~min}$. The harvested cells were washed several times with $\mathrm{N}$-free Zarrouk medium to completely remove the $\mathrm{N}$. Then the collected algal cells were re-inoculated into eight nitrogen concentrations set as $0.11,0.46,1.84,7.35$, $29.41,58.82,117.65,235.29 \mathrm{mM}$ (that was $1 / 256,1 / 64,1 / 16,1 / 4$, $1,2,4,8$-folds of the standard nitrogen concentration of Zarrouk medium, respectively), and used as inoculum at 0.2 of OD750.

\section{Growth Analysis}

$5 \mathrm{~mL}$ culture samples were taken out and filtered at each sampling time point through a pre-weighed $\mathrm{GF} / \mathrm{C}$ glass microfiber filter $\left(\mathrm{W}_{1}\right)$, then washed three times with triple distilled water to remove salts. After the filter was placed at $65^{\circ} \mathrm{C}$ for more than $6 \mathrm{~h}$, it was transferred to a drying dish and weighed again after cooling $\left(\mathrm{W}_{2}\right)$. The difference between $\mathrm{W}_{2}$ and $\mathrm{W}_{1}$ was the dry weight (DW) (Zhang et al., 2001). The algal cells cultured for 0 , $2,4,6$, and 7 days were collected by centrifugation to determine the biomass and calculate the specific growth rate. Based on the measured biomass, the specific growth rate was calculated as follows:

$$
\mu=\left(\ln \mathrm{N}_{2}-\ln \mathrm{N}_{1}\right) /\left(\mathrm{t}_{2}-\mathrm{t}_{1}\right)
$$

where $\mathrm{N}_{2}$ and $\mathrm{N}_{1}$ are the biomass at time $t_{2}$ and $\mathrm{t}_{1}$, respectively. 


\section{Determination of Photosynthetic Performance}

The maximum photochemical quantum yield $(F v / F m)$ and the non-photochemical quenching (NPQ) respectively, reflected the light energy absorbed by PS II in the form of heat dissipation and the maximum photosynthetic capacity of PS II (Farquhar et al., 1989; Tan et al., 2019). After being placed in the dark for $20 \mathrm{~min}$, $2 \mathrm{~mL}$ samples were transferred to a pulse amplitude-modulated (PAM) fluorometer (Water-PAM fluorometer, Walz, Effeltrich, Germany) to measure Chlorophyll fluorescence parameters of photosystem II (PSII). The values of $F v / F m$ and NPQ were obtained by analyzing the induction curves.

\section{Measurements of Total Lipid Content and Productivity}

Lipids were extracted according to a modified method described by Bligh and Dyer (1959). The microalgae liquid was collected by centrifugation at $4,500 \times \mathrm{g}$ and lyophilized overnight by an ALPHA 1-4 LD freeze dryer (Christ, Osterod, Germany). $50 \mathrm{mg}$ of freeze-dried algal powder were weighed correctly into a $100 \mathrm{~mL}$ centrifuge tube and crushed three times with an ultrasonic cell crusher (25\% power for $20 \mathrm{~min}$ ). Extraction was performed using $3 \mathrm{~mL}$ of chloroform and methanol at a proportion of 2:1 (v/v). Next, $1.2 \mathrm{ml}$ of $0.9 \% \mathrm{NaCl}$ was added to the extract combined three times. Finally, the lower layer (sediment) of the mixture was collected with a weighted glass tube $\left(\mathrm{W}_{1}\right)$ and placed in a $60^{\circ} \mathrm{C}$ water bath pot overnight and then taken out for weighing $\left(\mathrm{W}_{2}\right)$. The lipid content (LC,\%) and productivity (TLP, $\mathrm{mg} \mathrm{L}^{-1} \mathrm{~d}^{-1}$ ) were calculated as follows:

$$
\begin{gathered}
\mathrm{LC}=\left(\mathrm{W}_{2}-\mathrm{W}_{1}\right) / 50 * 100 \% \\
\mathrm{TLP}=\mathrm{W}_{\mathrm{A}} * \mathrm{LC} / \mathrm{T}
\end{gathered}
$$

where $\mathrm{W}_{\mathrm{A}}$ is the biomass $\left(\mathrm{mg} \mathrm{L}^{-1}\right)$ and $\mathrm{T}$ is the culture time (day).

\section{Measurements of Fucoxanthin Content and Productivity}

Fx was extracted according to methods described by Kim et al. (2012a) with modifications. The whole process of extraction was carried out under dim conditions. $10 \mathrm{mg}$ algae powder was accurately weighed and put into a $2 \mathrm{ml}$ grinding tube together with six steel balls and treated with a biological sample homogenizer. The crushed samples were added with $1 \mathrm{ml}$ absolute ethanol and extracted in an Oscillating incubator under ice bath conditions for $1 \mathrm{~h}$. After the Oscillating extraction, the mixture was centrifuged at 5,000 $\times \mathrm{g}$ for $8 \mathrm{~min}$.

The supernate was filtered through $0.45 \mu \mathrm{m}$ PTFE filters, and Fx was analyzed by RP-HPLC (reversed-phase high-performance liquid chromatography) using a YMC Carotenoid column (C30, $3.5,150 \times 4.6 \mathrm{~mm}$ I.D.). The column temperature was set at $25.0^{\circ} \mathrm{C}$ and the injection volume was $10 \mu \mathrm{L}$. For the Fx assay, $90 \%$ acetonitrile and ethyl acetate were used as the mobile phase and operated at a flow rate of $1 \mathrm{ml} / \mathrm{min}$. Under these conditions, the maximum absorbance of standard Fx (Sigma Aldrich) was obtained at $440 \mathrm{~nm}$. The Fx productivity (FxP, mg L $\left.\mathrm{L}^{-1} \mathrm{~d}^{-1}\right)$ was calculated as follows:

$$
\mathrm{FxP}=\mathrm{W}_{\mathrm{A}} * \mathrm{FxC} / \mathrm{T}
$$

where $\mathrm{W}_{\mathrm{A}}$ is the biomass $\left(\mathrm{mg} \mathrm{L}^{-1}\right), \mathrm{FxC}$ is the Fx content (mg $\mathrm{g}^{-1}$ ), and $\mathrm{T}$ is the culture time (day).

\section{Determination of Fatty Acid Composition}

Fatty acid methyl esters (FAME) were analyzed using gas chromatography (Agilent 6890 Series GC System; US10251016; Agilent, Santa Clara, CA, United States) after transmethylation according to a method described by Lepage and Roy (1984). The FAME composition was used to compute the degree of unsaturation (DU), the cetane number (CN), long-chain saturation factor (LCSF) and cold filter plugging point (CFPP), which were important indicators to expect the combustion performance of biofuel (Ramos et al., 2009).

\section{Statistical Analysis}

Three replicates were set for each treatment, and all results were calculated by Origin 2018 and expressed as mean \pm standard deviation (SD). SPSS Statistics software program (version 23) was used for one-way ANOVA at the significance level of $p<0.05$ to calculate the salient difference between treatments.

\section{RESULTS}

\section{Growth and Photosynthetic Performance}

The Growth curves, specific growth rate and photosynthetic parameters during 7 days of batch growth for Nitzschia sp. NW129 under different nitrogen concentrations were summarized in Figures 1A-D. When the concentration was more than $29.41 \mathrm{mM}$, the growth rate of the experimental groups was fast, and there was no significant difference in the specific growth rate throughout the whole process of cultivation, which corresponded to a consistent trend in NPQ values. Although $\mathrm{Fv} / \mathrm{Fm}$ always ranged approximately from 0.60 to 0.66 at nitrogen concentrations $\geq 1.84 \mathrm{mM}$, which the rapidly increasing NPQ values at concentrations of 1.84 and $7.35 \mathrm{mM}$ from the third day indicated that increased damage to PSII and greater dissipation of absorbed light energy in the form of heat, in accordance with almost no growth or even death of algal cells on the last day. Besides that, it was observed that a strong decrease of the growth rate and $\mathrm{Fv} / \mathrm{Fm}$ when algae were cultured at concentrations of 0.11 and $0.46 \mathrm{mM}$ after 2 days, and the increase of NPQ values accelerated with more extension of cultivation time. Moreover, the lower the nitrogen concentration in the range of concentrations less than $29.41 \mathrm{mM}$ at the end of the culture period, the higher the NPQ value, which indicated that the growth of algal cells was stressed by nitrogen limitation.

\section{Variation in Fucoxanthin Accumulation}

As shown in Table 1, the higher nitrogen concentrations could dramatically promote the accumulation of Fx content of Nitzschia sp. NW129. Concentrations had no pronounced effect 


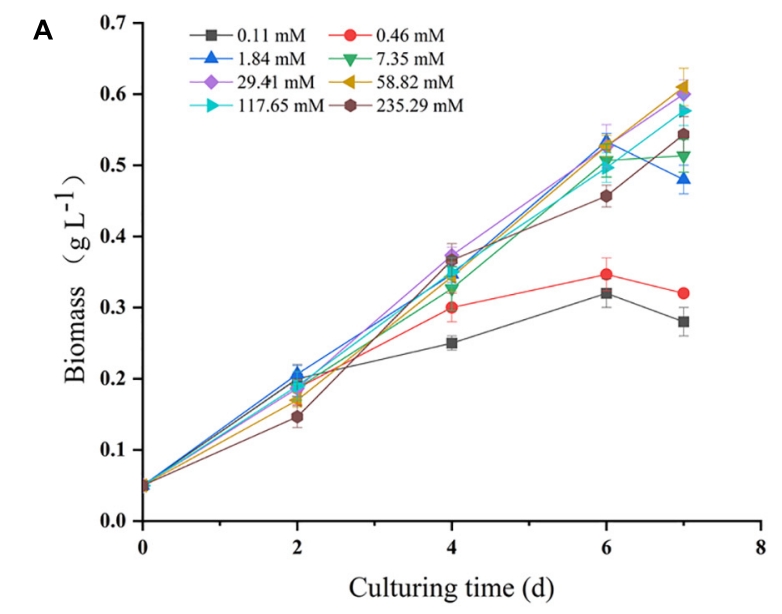

C

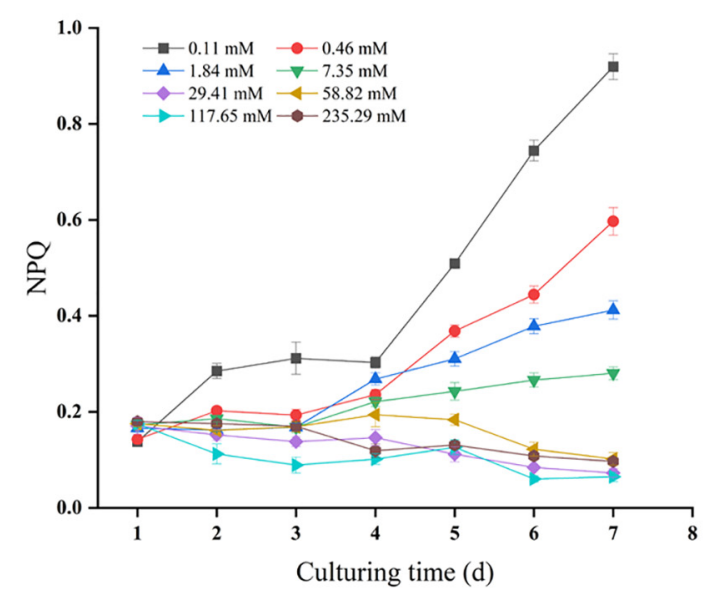

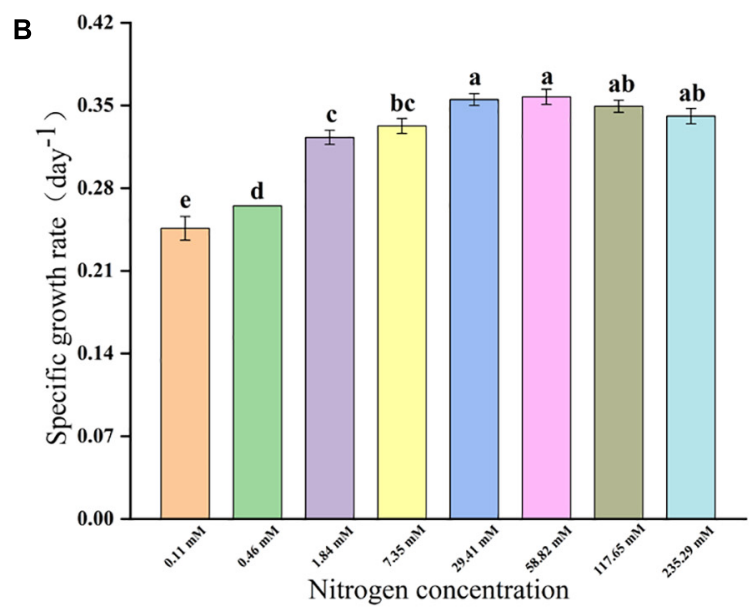

D

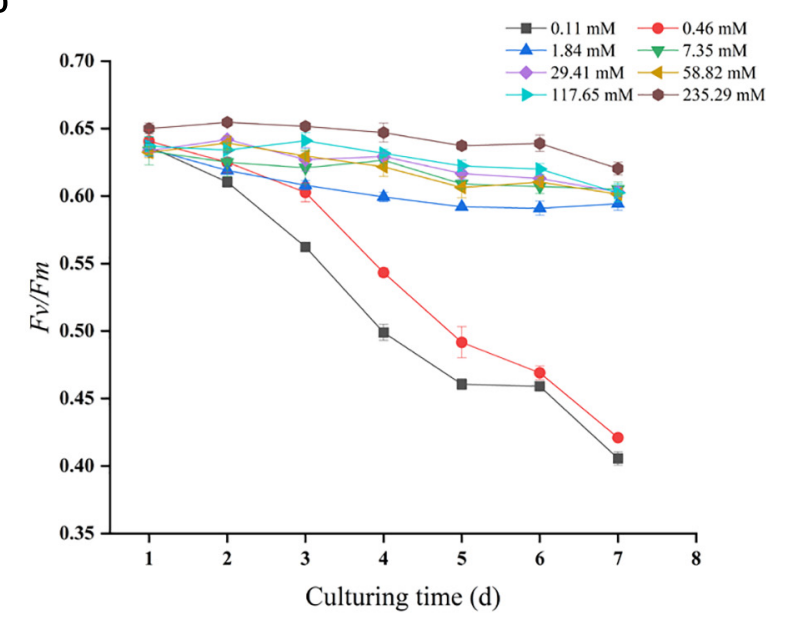

FIGURE 1 | Growth and photosynthetic performance of Nitzschia sp. NW129 under different nitrogen concentrations. Growth curves (A). Specific growth rate (B). Non-photochemical quenching (NPQ) (C). Maximum quantum yield (Fv/Fm) (D). Values are given as mean $\pm \mathrm{SD}, n=3$. Letters indicate statistical differences, which was analyzed by a one-way ANOVA with an alpha value of 0.05 .

on the Fx content at concentrations $\leq 0.46 \mathrm{mM}$, but when the concentration rose to $1.84 \mathrm{mM}$, the $\mathrm{Fx}$ content immediately increased to $9.11 \pm 0.15 \mathrm{mg} \mathrm{g}^{-1}$, which was 3.3 times higher than that of $0.46 \mathrm{mM}\left(2.77 \pm 0.06 \mathrm{mg} \mathrm{g}^{-1}\right)$. The maximum Fx content of $18.18 \pm 0.10 \mathrm{mg} \mathrm{g}^{-1}$ was observed at the concentration of $235.29 \mathrm{mM}$, which was 1.2 times than that at the standard nitrogen concentration of $117.65 \mathrm{mM}$. The Fx productivity increased apparently with increasing nitrogen concentrations from 0.11 to $117.65 \mathrm{mM}$, but there was no significant difference among the standard nitrogen concentration $\left(1.32 \pm 0.04 \mathrm{mg} \mathrm{d}^{-1}\right)$ and the higher concentrations except $117.65 \mathrm{mM}$ (Table 1). The Fx content at the concentration of $235.29 \mathrm{mM}$ had no prominent difference in comparison with that at the concentration of $117.65 \mathrm{mM}$, but its growth was inhibited by excessive nitrogen to a certain extent, bringing about a slightly lower productivity.

\section{Variation in Lipid Accumulation}

Opposite to the Fx content, the lipid content of Nitzschia sp. NW129 was enhanced obviously within a certain range in response to the decrease of nitrogen concentration (Table 1). The maximum lipid content $40.67 \pm 1.04 \%$ DW was observed at the concentration of $0.11 \mathrm{mM}$, which was 1.7 fold higher than that in the standard nitrogen concentration of Zarrouk medium. No considerable difference in lipid content was observed at concentrations $\leq 0.46$ and $\geq 1.84 \mathrm{mM}$, respectively. With concentrations increased from 0.46 to $1.84 \mathrm{mM}$, the lipid content decreased from $36.50 \pm 1.80$ to $25.67 \pm 2.67 \%$ DW (30\%). Changes in productivities differed from the trend in content (Table 1). Due to the fact that low concentrations promoted an increase in content but markedly reduced biomass, lipid productivity showed an increase followed by a decrease with increasing nitrogen concentrations. Thus, the lipid productivity at the concentration of $0.11 \mathrm{mM}$ was the lowest in spite that the lipid content at this concentration was maximum. The maximum lipid productivity attained $20.290 \pm 0.902 \mathrm{mg} \mathrm{L}^{-1}$ $\mathrm{d}^{-1}$ at the concentration of $29.41 \mathrm{mM}$, but there were no significant difference among experimental groups of the nitrogen concentrations higher than $29.41 \mathrm{mM}$. 
TABLE 1 | Final biomass, lipid and fucoxanthin (Fx) productivities of Nitzschia sp. NW129 grown under different nitrogen concentrations.

\begin{tabular}{|c|c|c|c|c|c|}
\hline $\begin{array}{l}\text { Nitrogen } \\
\text { concentration }\end{array}$ & Final Biomass $\left(\mathrm{g} \mathrm{L}^{-1}\right)$ & $\begin{array}{l}\text { Lipid content ( } \% \text { of } \\
\text { dry weight) }\end{array}$ & $\begin{array}{l}\text { Lipid productivity } \\
\qquad\left(\mathrm{mg} \mathrm{L}^{-1} \mathrm{~d}^{-1}\right)\end{array}$ & Fx content $\left(\mathrm{mg} \mathrm{g}^{-1}\right)$ & $\begin{array}{l}\text { Fx productivity (mg } \\
\mathrm{L}^{-1} \mathrm{~d}^{-1} \text { ) }\end{array}$ \\
\hline $0.11 \mathrm{Mm}$ & $0.28 \pm 0.02^{e}$ & $40.67 \pm 1.04^{\mathrm{a}}$ & $16.26 \pm 1.15^{c}$ & $2.21 \pm 0.11^{e}$ & $0.09 \pm 0.01^{e}$ \\
\hline $0.46 \mathrm{mM}$ & $0.32 \pm 0.00^{e}$ & $36.50 \pm 1.80^{a}$ & $16.69 \pm 0.82^{b c}$ & $2.77 \pm 0.06^{e}$ & $0.13 \pm 0.00^{e}$ \\
\hline $1.84 \mathrm{mM}$ & $0.48 \pm 0.02^{d}$ & $25.67 \pm 2.47^{b}$ & $17.56 \pm 1.03^{a b c}$ & $9.11 \pm 0.15^{d}$ & $0.63 \pm 0.02^{d}$ \\
\hline $7.35 \mathrm{mM}$ & $0.51 \pm 0.02^{\mathrm{cd}}$ & $24.33 \pm 1.44^{b}$ & $17.88 \pm 1.89^{a b c}$ & $12.44 \pm 0.19^{c}$ & $0.91 \pm 0.05^{c}$ \\
\hline $29.41 \mathrm{mM}$ & $0.60 \pm 0.02^{a b}$ & $23.67 \pm 0.29^{b}$ & $20.29 \pm 0.90^{\mathrm{a}}$ & $15.44 \pm 0.14^{b}$ & $1.32 \pm 0.04^{b}$ \\
\hline $58.82 \mathrm{mM}$ & $0.61 \pm 0.03^{a}$ & $23.31 \pm 1.32^{b}$ & $20.28 \pm 0.33^{a}$ & $15.73 \pm 0.35^{b}$ & $1.37 \pm 0.06^{a b}$ \\
\hline $117.65 \mathrm{mM}$ & $0.58 \pm 0.02^{a b}$ & $23.98 \pm 2.10^{b}$ & $19.95 \pm 1.29^{a}$ & $17.55 \pm 1.13^{\mathrm{a}}$ & $1.44 \pm 0.05^{a}$ \\
\hline $235.29 \mathrm{mM}$ & $0.54 \pm 0.03^{b c}$ & $25.19 \pm 2.18^{b}$ & $19.51 \pm 0.94^{a b}$ & $18.18 \pm 0.10^{a}$ & $1.41 \pm 0.06^{a b}$ \\
\hline
\end{tabular}

Values mean $\pm S D(n=3)$. Values with the different letters indicate a significant difference between them $(p<0.05)$.

\section{Variation in Fatty Acid Profiles and Biofuel Quality}

The fatty acid profile and some biofuel indicators of Nitzschia sp. at three concentrations were summarized in Table 2. In this study, C14 to C16 were dominant in the FAME of isolated Nitzschia sp. Obviously, the content of saturated fatty acids (SFA) and unsaturated fatty acids was disparity under different nitrogen concentrations. Only eight fatty acids without polyunsaturated fatty acids (PUFA) were detected at the concentration of $0.11 \mathrm{mM}$, which contributed to the lowest DU of 10. Compared with the standard nitrogen concentration, the proportion of myristic acid (C14:0) decreased from 46.06 to $19.49 \%$ and pentadecanoic acid (C15:0) increased from 1.39 to $26.20 \%$ at the concentration of $0.11 \mathrm{mM}$. The percentage composition of SFA, Monounsaturated fatty acids (MUFA) and PUFA of Nitzschia sp. cultivated in the standard nitrogen concentration were 84.93, 12.59 , and $2.21 \%$, respectively. The increase of concentrations markedly contributed to the accumulation of unsaturated fatty acids, the highest values of $40.83 \%$ MUFA and $4.57 \%$ PUFA were observed at the concentration of $117.65 \mathrm{mM}$. Compared to the standard nitrogen concentration, the ginkgolic Acid (C15:1) and palmitoleic acid (C16:1) increased from 6.40 to $10.19 \%$ and from 0.37 to $25.58 \%$, respectively, which led to higher DU value of 49.97 at the concentration of $117.65 \mathrm{mM}$. The nitrogen enrichment also promoted the increase of fatty acid species and the production of eicosapentaenoic acid (EPA). The CN value at the concentrations of $117.65 \mathrm{mM}$ were saliently lower compared to standard nitrogen concentration. In addition, the extremely low content of long-chain saturated fatty acids under three treatments resulted in lower LCSF and CFPP.

\section{DISCUSSION}

Nitrogen, known as "life element," is a macronutrient essential for algal growth and the production of lipids, pigments, terpenes and other substances. The genes encoding photosynthesisrelated proteins in diatoms were significantly down-regulated under nitrogen deficiency conditions (Hockin et al., 2012; Yang et al., 2013). Meanwhile, the lack of nitrogen also triggered the degradation of nitrogen-containing compounds such as chlorophyll and entrained cellular chlorosis (Pancha et al., 2014).
Therefore, the weakened photoreaction diminished the $5^{\prime}$ Adenylate triphosphate (ATP) and nicotinamide adenine dinucleotide phosphate (NADPH) necessary for carbon fixation, which led to the reduction of carbon dioxide fixed by algal cells and ultimately the reduction of biomass. NPQ mediated and $\mathrm{Fv} / \mathrm{Fm}$ could be useful indicators for judging the nutritional limitation and stress degree of algal cells (Ruban et al., 2004). The high NPQ and low $F v / F m$ values were frequently observed in plants under stress conditions, which indicated that the process of photosynthesis was hindered and more energy flew to heat dissipation (Li et al., 2020). In this study, the biomass and $\mathrm{Fv} / \mathrm{Fm}$ at concentrations of 0.11 and $0.46 \mathrm{mM}$ were significantly lower than those under higher concentrations, while NPQ was opposite. Compared with the nitrogen concentration of the standard nitrogen concentration of Zarrouk medium, the distinctly reduced specific growth rate concurred with the higher NPQ value at concentrations of 1.84 and $7.35 \mathrm{mM}$, which suggested that nitrogen deficiency restrained the growth and photosynthesis of algal cells. Furthermore, the biomass at concentrations $\geq 117.65 \mathrm{mM}$ was slightly lower in comparison with that at the standard nitrogen concentration, which may be because the growth of algal cells was suppressed by the excessive nitrate in the culture medium (Feng et al., 2011).

It has been documented that $\mathrm{Fx}$ has high antioxidant capacity due to its allyl bond and six oxygen atoms, especially in a hypoxic environment (Peng et al., 2011). Heo et al. (2008) found that Fx could effectively inhibit the generation of reactive oxygen species by increasing catalase activity, thereby having antioxidant activity, preventing DNA damage and $\mathrm{H}_{2} \mathrm{O}_{2}$-induced fineness apoptosis. The gradual reduction of Fx content with decreasing the nitrogen concentrations in this study was similar to the response of Phaeodactylum tricornutum to nitrogen consumption (Gao et al., 2017). The mRNA level of genes encoding photosynthetic protein decreased remarkably under $\mathrm{N}$ restriction (Yang et al., 2013). Longworth et al. (2016) discovered that the relative abundances of light-harvesting proteins decreased under nitrogen stress. Fx combined with chlorophyll a/c to form fucoxanthin-chlorophyll a/c protein complex (FCP) in diatoms, the FCP existed in the thylakoid and played a role in light capture and light transmission (Wang et al., 2005), which had a high content of nitrogen. Therefore, under conditions of nitrogen scarcity, cells tend to degrade them actively to reuse nitrogen and transfer it to the synthesis of those proteins that are indispensable 
TABLE 2 | Effects of different nitrogen concentrations on the fatty acid profiles and biofuel quality of Nitzschia sp. NW129.

\begin{tabular}{|c|c|c|c|}
\hline \multirow[t]{2}{*}{ Fatty acid } & \multicolumn{3}{|c|}{ Fatty acid content $(\% \mathrm{w} / \mathrm{w})$} \\
\hline & $0.11 \mathrm{mM}$ & $29.41 \mathrm{mM}$ & $117.65 \mathrm{mM}$ \\
\hline $\mathrm{C} 4: 0$ & $0.92 \pm 0.02^{\mathrm{a}}$ & $0.05 \pm 0.01^{c}$ & $0.14 \pm 0.01^{b}$ \\
\hline C6:0 & $4.81 \pm 0.04^{a}$ & $0.21 \pm 0.02^{\mathrm{C}}$ & $0.29 \pm 0.02^{b}$ \\
\hline C12:0 & ND & $0.19 \pm 0.01$ & ND \\
\hline C14:0 & $19.49 \pm 0.73^{b}$ & $46.06 \pm 0.28^{a}$ & $13.48 \pm 0.15^{c}$ \\
\hline C15:0 & $26.20 \pm 1.16^{a}$ & $1.39 \pm 0.05^{b}$ & $1.10 \pm 0.03^{b}$ \\
\hline C16:0 & $37.89 \pm 0.64^{a}$ & $35.70 \pm 0.11^{b}$ & $35.98 \pm 0.45^{b}$ \\
\hline C18:0 & ND & $0.62 \pm 0.03^{b}$ & $1.38 \pm 0.07^{a}$ \\
\hline C20:0 & ND & $0.05 \pm 0.01^{b}$ & $0.26 \pm 0.02^{a}$ \\
\hline $\mathrm{C} 22: 0$ & ND & $0.26 \pm 0.03^{a}$ & $0.16 \pm 0.02^{b}$ \\
\hline C23:0 & ND & ND & $1.02 \pm 0.02$ \\
\hline $\mathrm{C} 24: 0$ & ND & $0.22 \pm 0.01^{b}$ & $0.61 \pm 0.02^{a}$ \\
\hline C14:n-5 & $0.43 \pm 0.01^{c}$ & $0.73 \pm 0.03^{b}$ & $1.14 \pm 0.06^{a}$ \\
\hline C15:n-5 & $9.24 \pm 0.03^{b}$ & $6.40 \pm 0.07^{\mathrm{c}}$ & $10.19 \pm 0.09^{a}$ \\
\hline C16:n-7 & $0.33 \pm 0.02^{b}$ & $0.37 \pm 0.02^{b}$ & $25.58 \pm 0.16^{a}$ \\
\hline C17:n-7 & ND & $2.26 \pm 0.07^{a}$ & $1.12 \pm 0.04^{b}$ \\
\hline C18:n-9 & ND & $1.45 \pm 0.02^{b}$ & $1.71 \pm 0.05^{a}$ \\
\hline C18:n-9 & ND & $0.70 \pm 0.01^{b}$ & $1.02 \pm 0.04^{a}$ \\
\hline C22:n-9 & ND & $0.68 \pm 0.02^{b}$ & $0.08 \pm 0.01^{a}$ \\
\hline C18:2n-6 & ND & $0.08 \pm 0.01^{\mathrm{b}}$ & $0.24 \pm 0.01^{a}$ \\
\hline C18:2n-6 & ND & $0.05 \pm 0.01^{b}$ & $0.26 \pm 0.02^{a}$ \\
\hline C18:3n-6 & ND & $0.01 \pm 0.00^{b}$ & $0.15 \pm 0.01^{a}$ \\
\hline C20:3n-3 & ND & $2.08 \pm 0.03^{a}$ & $1.00 \pm 0.02^{b}$ \\
\hline C20:5n-3 & ND & ND & $2.82 \pm 0.09$ \\
\hline SFA & $89.40 \pm 0.89^{a}$ & $84.93 \pm 0.45^{b}$ & $54.41 \pm 0.65^{c}$ \\
\hline MUFA & $10.00 \pm 0.05^{c}$ & $12.59 \pm 0.07^{b}$ & $40.83 \pm 0.28^{a}$ \\
\hline PUFA & ND & $2.21 \pm 0.03^{b}$ & $4.57 \pm 0.12^{a}$ \\
\hline DU & $10.00 \pm 0.05^{c}$ & $17.01 \pm 0.11^{b}$ & $49.97 \pm 0.46^{a}$ \\
\hline $\mathrm{CN}$ & $64.63 \pm 0.56^{b}$ & $66.79 \pm 0.26^{a}$ & $62.72 \pm 0.53^{c}$ \\
\hline LCSF & $3.79 \pm 0.06^{c}$ & $4.76 \pm 0.07^{b}$ & $6.00 \pm 0.05^{a}$ \\
\hline CFPP & $-4.57 \pm 0.20^{c}$ & $-1.52 \pm 0.22^{b}$ & $2.37 \pm 0.17^{\mathrm{a}}$ \\
\hline
\end{tabular}

SFA, saturated fatty acids; MUFA, monounsaturated fatty acids; PUFA, polyunsaturated fatty acids; DU, degree of unsaturation, $D U=($ MUFA +2 PUFA); $C N$, cetane number; LCSF, long chain saturated factor, LCSF $=0.1 \times C 16: 0(\%)$ $+0.5 \times C 18: 0(\%)+1 \times C 20: 0(\%)+1.5 \times C 22: 0(\%)+2 \times C 24: 0(\%) ; C F P P$, cold filter plugging point, $C F P P=(3.1417 \times L C S F)-16.477 ; N D$, below the limit of detection.

Each data value represents the mean $\pm S D$ of three replications. Values with the different letters indicate a significant difference between them $(p<0.05)$.

for cell survival. $P$. tricornutum with high $\mathrm{Fx}$ content (0.2$16.51 \mathrm{mg} \mathrm{g}^{-1}$ ) has been widely concerned, which was several times more abundant than that in macroalgae (Kim et al., 2012a; Gomez-Loredo et al., 2016; Wu et al., 2016; Ishika et al., 2017; Gao et al., 2020). It has been reported that Fx content obtained from Nitzschia sp. was from 0.49 to $12 \mathrm{mg} \mathrm{g}^{-1}$ (Kim et al., 2012b; Guo et al., 2016; Lu et al., 2018; Sahin et al., 2019). The Fx content of Nitzschia sp. NW129 was higher under the nitrogen enrichment conditions, consistent with Sahin et al. (2019) on the noticeable increase in Fx content caused by nitrate supplementation to Nitzschia sp. Compared with other reports on Nitzschia sp., the highest Fx content of Nitzschia sp. NW129 was $18.176 \mathrm{mg} \mathrm{g}^{-1}$, indicating that it cultured under high nitrogen conditions had better potential for Fx production.

In previous studies, the effects of nitrogen deficiency on lipid accumulation were species-specific. Carbohydrates, the primary energy storage substances in Odontella aurita and Arthrospira platensis under nitrogen-limited conditions, increased rather than lipids (Panyakampol et al., 2016; Xia et al., 2018). However, the lipid content of most microalgae increased under nitrogen limitation (Shifrin and Chisholm, 2010). For example, the lipid content of Chlorella vulgaris and Nannochloropsis oculata cultured under nutrients-stress conditions increased by 2-3fold compared to the high nitrogen concentration (Converti et al., 2009). In agreement with the above results, in the present study, a lipid content of $40.67 \%$ was observed at the lowest nitrogen concentration, which was 1.7 times higher than that at standard nitrogen concentration. Under nitrogenlimited conditions, most genes related to photosynthesis and chlorophyll biosynthesis were inhibited, and a variety of roles in carbon metabolism were changed, such as the down-regulation of Calvin cycle, the up-regulation of glycolysis and tricarboxylic acid cycle, generating more carbon sources flowing into lipid metabolism (Alipanah et al., 2015). Nitrogen concentrations affected not only lipid content but also the fatty acid composition of diatoms greatly, which determined the quality of biofuel. CFPP, the temperature of filter blockage caused by crystallization of fuel, was generally acknowledged as an important indicator to measure the performance of biofuel in the global biofuel industry (Gomez-Rodriguez et al., 2021). The low CFPP obtained at three concentrations met European standards (EN14214) and represented a superior cold flow property of the biofuel (Stansell et al., 2012). The sum of SFA and MUFA contents of the Nitzschia sp. NW129 exceeded 90\% under different nitrogen concentrations, which was in accordance with the previous results (Sahin et al., 2019). It was reported that high nitrogen concentration generated greater accumulation of MUFA while the higher percentage of SFA and PUFA were observed under nitrogen deficiency (Qiao et al., 2016). Compared to the standard nitrogen concentration, the proportion of C14:0 decreased markedly whereas C15:1 and C16:1 was significantly increased at the concentration of $117.65 \mathrm{mM}$, which contributed to a higher DU value. The high DU value represented that the biofuel was more difficult to form deposits and had better lubricity (Qiao et al., 2021). The maximum and minimum values of DU and CN should be 137 and 51, respectively (EN14214). DU and $\mathrm{CN}$ values under three nitrogen concentrations were in accordance with it. Furthermore, the content of linolenic acid (C18:3) under three treatments was less than 12\% limited in EN14214 (Chisti, 2007). The fatty acid profile indicated that Nitzschia sp. NW129 was a potential candidate for biofuel production.

Productivity, determined by a combination of biomass and content, was a crucial quality in selecting strains for largescale production of high-value materials (Griffiths and Harrison, 2009). Therefore, the effects of nutritional conditions on biomass and content needed to be taken into account together. The lipid content $(3.44-31.96 \%$ DW) of thirty microalgal strains under nitrogen deprivation conditions was higher than that under nitrogen-sufficient. Interestingly, 24 of them showed lower lipid productivities (0.085-4.560 $\left.\mathrm{mg} \mathrm{L}^{-1} \mathrm{~d}^{-1}\right)$ under nitrogen-free conditions. Andeden et al. (2021) reported that most microalgal strains in nitrogen-free cultivation showed 
lower lipid productivities compared with the nitrogen-sufficient condition. However, as nitrogen deficiency affected the biomass and lipid content in different microalgal species to different degrees, higher lipid productivities of 10 algae species such as Ankistrodesmus falcatus, Chlorella vulgaris, and Scenedesmus sp. in low nitrate-stress induced cultures were observed (Griffiths et al., 2012). As to Fx, the nitrogen enrichment generally promoted the accumulation of biomass and Fx content at the same time, which would undoubtedly increase Fx productivity (Sun et al., 2019). Interestingly, it was found that the higher Fx content was caused by high biomass concentration and higher biomass and Fx productivities were induced by low biomass concentration (Gao et al., 2020). These results suggested the microalgae presented different responses in terms of the productivities of lipid and Fx under nitrogen replete and limited conditions, which it was difficult to obtain high Fx and lipid productivities in the meantime. In the present study, the increase in nitrogen concentration was accompanied by an increase in lipid productivity, yet there was no significant difference in productivities between different nitrogen concentrations when concentrations were higher than $1.84 \mathrm{mM}$. The maximum Fx productivity of the Nitzschia sp. NW129 was $1.44 \pm 0.05 \mathrm{mg}$ $\mathrm{L}^{-1} \mathrm{~d}^{-1}$ at the concentration of $117.65 \mathrm{mM}$, which was saliently higher than the standard nitrogen concentration and 23 times more than P. tricornutum, Navicula sp., and Amphora sp. (Ishika et al., 2017; Wang et al., 2018b). Thus, the concentration of $117.65 \mathrm{mM}$ was considered the most suitable for simultaneous production of lipids and Fx in biorefinery. The overall performance of Nitzschia sp. NW129 at this concentration was equivalent to or higher than that of non-polar microalgae, which could be good producers of lipids or Fx.

\section{CONCLUSION}

In this study, an appropriate nitrogen concentration of $117.65 \mathrm{mM}$ was screened and excellent productivities of lipid

\section{REFERENCES}

Alipanah, L., Rohloff, J., Winge, P., Bones, A. M., and Brembu, T. (2015). Wholecell response to nitrogen deprivation in the diatom Phaeodactylum tricornutum. J. Exp. Bot. 66, 6281-6296. doi: 10.1093/jxb/erv340

Andeden, E. E., Ozturk, S., and Aslim, B. (2021). Evaluation of thirty microalgal isolates as biofuel feedstocks based on lipid productivity and triacylglycerol (TAG) content. Curr. Microbiol. 78, 775-788. doi: 10.1007/s00284-020-02 $340-5$

Bligh, E. G., and Dyer, W. J. (1959). A rapid method of total lipid extraction and purification. Can. J. Biochem. Physiol. 37, 911-917. doi: 10.1139/o59-099

Bondioli, P., Della, B. L., Rivolta, G., Zittelli, G. C., Bassi, N., Rodolfi, L., et al. (2012). Oil production by the marine microalgae Nannochloropsis sp F\&MM24 and Tetraselmis suecica F\&M-M33. Bioresour. Technol. 114, 567-572. doi: 10.1016/j.biortech.2012.02.123

Campenni', L., Nobre, B. P., Santos, C. A., Oliveira, A. C., Aires-Barros, M. R., Palavra, A. M. F., et al. (2013). Carotenoid and lipid production by the autotrophic microalga Chlorella protothecoides under nutritional, salinity, and luminosity stress conditions. Appl. Microbiol. Biotechnol. 97, 1383-1393. doi: 10.1007/s00253-012-4570-6

Chisti, Y. (2007). Biofuel from microalgae. Biotechnol. Adv. 25, 294-306. doi: 10.1016/j.biotechadv.2007.02.001 $\left(19.95 \pm 1.29 \mathrm{mg} \mathrm{L}^{-1} \mathrm{~d}^{-1}\right)$ and $\mathrm{Fx}\left(1.44 \pm 0.05 \mathrm{mg} \mathrm{L}^{-1} \mathrm{~d}^{-1}\right)$ were obtained from the alkalophilic microalga Nitzschia sp. NW129 simultaneously. Furthermore, this concentration induced the accumulation of unsaturated fatty acids, especially MUFA, resulting in superior biofuel properties. In a nutshell, these results demonstrated the feasibility of utilizing the alkalophilic microalgae for the integrated production of biofuels and Fx in biorefinery and emphasized the potential of Nitzschia sp. NW129 as a promising feedstock.

\section{DATA AVAILABILITY STATEMENT}

The original contributions presented in the study are included in the article/supplementary material, further inquiries can be directed to the corresponding author/s.

\section{AUTHOR CONTRIBUTIONS}

ZC: data curation and writing-original draft preparation. YL and BZ: writing - review and editing. XS: conceptualization. XW: formal analysis. YL: revision. KP: funding acquisition. All authors have read and agreed to the published version of the manuscript.

\section{FUNDING}

This research was funded by the National Key Research and Development Program of China (2016YFB0601001).

\section{ACKNOWLEDGMENTS}

We gratefully acknowledge the kind assistance of Ruihao Zhang and Xiufen Wang in writing the manuscript.

Converti, A., Casazza, A. A., Ortiz, E. Y., Perego, P., and Del Borghi, M. (2009). Effect of temperature and nitrogen concentration on the growth and lipid content of Nannochloropsis oculata and Chlorella vulgaris for biofuel production. Chem. Eng. Process. 48, 1146-1151. doi: 10.1016/j.cep.2009.03.006

Cui, J., Zhong, D. B., Zhao, Y. T., and Yu, X. Y. (2020). Melatonin and calcium act synergistically to enhance the coproduction of astaxanthin and lipids in Haematococcus pluvialis under nitrogen deficiency and high light conditions. Bioresour. Technol. 305:123069. doi: 10.1016/j.biortech.2020.123069

Farquhar, G. D., Wong, S. C., Evans, J. R., and Hubick, K. T. (1989). "Photosynthesis and gas exchange," in Plants Under Stress, eds H. G. Jones, T. J. Flowers, and M. B. Jones (Cambridge: Cambridge University Press), 47-69.

Feng, D. N., Chen, Z. A., Xue, S., and Zhang, W. (2011). Increased lipid production of the marine oleaginous microalgae Isochrysis zhangjiangensis (Chrysophyta) by nitrogen supplement. Bioresour. Technol. 102, 6710-6716. doi: 10.1016/j. biortech.2011.04.006

Gao, B. Y., Chen, A. L., Zhang, W. Y., Li, A. F., and Zhang, C. W. (2017). Coproduction of lipids, eicosapentaenoic acid, fucoxanthin, and chrysolaminarin by phaeodactylum tricornutum cultured in a flat-plate photobioreactor under varying nitrogen conditions. J. Ocean Univ. China 16, 916-924. doi: 10.1007/ s11802-017-3174-2

Gao, F. Z., Sa, M., Teles, I., Wijffels, R. H., and Barbosa, M. J. (2020). Production and monitoring of biomass and fucoxanthin with brown microalgae under 
outdoor conditions. Biotechnol. Bioeng. 118, 1355-1365. doi: 10.1002/bit.2 7657

Gomez-Loredo, A., Benavides, J., and Rito-Palomares, M. (2016). Growth kinetics and fucoxanthin production of Phaeodactylum tricornutum and Isochrysis galbana cultures at different light and agitation conditions. J. Appl. Phycol. 28, 849-860. doi: 10.1007/s10811-015-0635-0

Gomez-Rodriguez, K. A., Chavarria-Hernandez, J. C., and Martinez-Tapia, G. E. (2021). Estimation of cold flow properties of biofuel from fatty acid composition. Energ. Fuel. 35, 1442-1448. doi: 10.1021/acs.energyfuels.0c03237

Griffiths, M. J., and Harrison, S. T. L. (2009). Lipid productivity as a key characteristic for choosing algal species for biofuel production. J. Appl. Phycol. 21, 493-507. doi: 10.1007/s10811-008-9392-7

Griffiths, M. J., van Hille, R. P., and Harrison, S. T. L. (2012). Lipid productivity, settling potential and fatty acid profile of 11 microalgal species grown under nitrogen replete and limited conditions. J. Appl. Phycol. 24, 989-1001. doi: 10.1007/s10811-011-9723-y

Guo, B. B., Liu, B., Yang, B., Sun, P. P., Liu, X., Liu, J., et al. (2016). Screening of Diatom strains and characterization of Cyclotella cryptica as a potential fucoxanthin producer. Mar. Drugs 14:125. doi: 10.3390/md14070125

Guo, H., Li, T., Zhao, Y. T., and Yu, X. Y. (2021). Role of copper in the enhancement of astaxanthin and lipid coaccumulation in Haematococcus pluvialis exposed to abiotic stress conditions. Bioresour. Technol. 335:125265. doi: 10.1016/j. biortech.2021.125265

Heo, S. J., Ko, S. C., Kang, S. M., Kang, H. S., Kim, J. P., Kim, S. H., et al. (2008). Cytoprotective effect of fucoxanthin isolated from brown algae Sargassum siliquastrum against H2O2-induced cell damage. Eur. Food Res. Technol. 228, 145-151. doi: 10.1007/s00217-008-0918-7

Hockin, N. L., Mock, T. F., Mulholland, F., Kopriva, S., and Malin, G. (2012). The response of Diatom central carbon metabolism to nitrogen starvation is different from that of green algae and higher plants. Plant Physiol. 158, 299-312. doi: 10.1104/pp.111.184333

Ishika, T., Moheimani, N. R., Bahri, P. A., Laird, D. W., Blair, S., and Parlevliet, D. (2017). Halo-adapted microalgae for fucoxanthin production: effect of incremental increase in salinity. Algal Res. 28, 66-73. doi: 10.1016/j.algal.2017. 10.002

Kim, S. M., Jung, Y. J., Kwon, O. N., Cha, K. H., Um, B. H., Chung, D., et al. (2012a). A potential commercial source of fucoxanthin extracted from the microalga Phaeodactylum tricornutum. Appl. Biochem. Biotechnol. 166, 1843-1855. doi: 10.1007/s12010-012-9602-2

Kim, S. M., Kang, S. W., Kwon, O. N., Chung, D., and Pan, C. H. (2012b). Fucoxanthin as a major carotenoid in Isochrysis aff. galbana: characterization of extraction for commercial application. J. Korean Soc. Appl. Biol. Chem. 55, 477-483. doi: 10.1007/s13765-012-2108-3

Kuo, C. M., Lin, T. H., Yang, Y. C., Zhang, W. X., Lai, J. T., Wu, H. T., et al. (2017). Ability of an alkali-tolerant mutant strain of the microalga Chlorella sp. AT1 to capture carbon dioxide for increasing carbon dioxide utilization efficiency. Bioresour. Technol. 244, 243-251. doi: 10.1016/j.biortech.2017.07.096

Lai, Y. C., Karam, A. L., Sederoff, H. W., Ducoste, J. J., and de los Reyes, F. L. (2019). Relating nitrogen concentration and light intensity to the growth and lipid accumulation of Dunaliella viridis in a photobioreactor. J. Appl. Phycol. 31, 3397-3409. doi: 10.1007/s10811-019-01897-4

Lepage, G., and Roy, C. C. (1984). Improved recovery of fatty acid through direct transesterification without prior extraction or purification. J. Lipid Res. 25, 1391-1396. doi: 10.1089/jir.1984.4.635

Li, J., Tang, X. X., Pan, K. H., Zhu, B. H., Li, Y., Ma, X. B., et al. (2020). The regulating mechanisms of $\mathrm{CO} 2$ fixation and carbon allocations of two Chlorella sp. strains in response to high CO2 levels. Chemosphere 247:125814. doi: 10. 1016/j.chemosphere.2020.125814

Liu, J., Mao, X. M., Zhou, W. G., and Guarnieri, M. T. (2016). Simultaneous production of triacylglycerol and high-value carotenoids by the astaxanthinproducing oleaginous green microalga Chlorella zofingiensis. Bioresour. Technol. 214, 319-327. doi: 10.1016/j.biortech.2016.04.112

Longworth, J., Wu, D. Y., Huete-Ortega, M., Wright, P. C., and Vaidyanathan, S. (2016). Proteome response of Phaeodactylum tricornutum, during lipid accumulation induced by nitrogen depletion. Alagl Res. 18, 213-224. doi: 10 . 1016/j.algal.2016.06.015

Lu, X., Sun, H., Zhao, W. Y., Cheng, K. W., Chen, F., and Liu, B. (2018). A hetero-photoautotrophic two-stage cultivation process for production of fucoxanthin by the marine diatom Nitzschia laevis. Mar. Drugs 16:219. doi: $10.3390 / \mathrm{md} 16070219$

Malviya, S., Scalco, E., Audic, S., Vincenta, F., Veluchamy, A., Poulain, J., et al. (2016). Insights into global diatom distribution and diversity in the world's ocean. Proc. Natl. Acad. Sci. U.S.A. 113, E1516-E1525. doi: 10.1073/pnas. 1509523113

Mohamadnia, S., Tavakoli, O., Faramarzi, M. A., and Shamsollahi, Z. (2020). Production of fucoxanthin by the microalga Tisochrysis lutea: a review of recent developments. Aquaculture 516:734637. doi: 10.1016/j.aquaculture.2019. 734637

Pancha, I., Chokshi, K., George, B., Ghosh, T., Paliwal, C., Maurya, R., et al. (2014). Nitrogen stress triggered biochemical and morphological changes in the microalgae Scenedesmus sp. CCNM 1077. Bioresour. Technol. 156, 146-154. doi: 10.1016/j.biortech.2014.01.025

Panyakampol, J., Cheevadhanarak, S., Senachak, J., Dulsawat, S., Siangdung, W., and Tanticharoen, M. (2016). Different effects of the combined stress of nitrogen depletion and high temperature than an individual stress on the synthesis of biochemical compounds in Arthrospira platensis C1 (PCC 9438). J. Appl. Phycol. 28, 2177-2186. doi: 10.1007/s10811-015-0765-4

Peng, J., Yuan, J. P., Wu, C. F., and Wang, J. H. (2011). Fucoxanthin, a marine carotenoid present in brown seaweeds and Diatoms: metabolism and bioactivities relevant to human health. Mar. Drugs 9, 1806-1828. doi: 10.3390/ md9101806

Peng, L. C., Lan, C. Q., Zhang, Z. S., Sarch, C., and Laporte, M. (2015). Control of protozoa contamination and lipid accumulation in Neochloris oleoabundans culture: effects of $\mathrm{pH}$ and dissolved inorganic carbon. Bioresour. Technol. 197, 143-151. doi: 10.1016/j.biortech.2015.07.101

Qiao, H. J., Cong, C., Sun, C. X., Li, B. S., Wang, J. Y., and Zhang, L. M. (2016). Effect of culture conditions on growth, fatty acid composition and DHA/EPA ratio of Phaeodactylum tricornutum. Aquaculture 452, 311-317. doi: 10.1016/j. aquaculture.2015.11.011

Qiao, T. S., Zhao, Y. T., Han, B. Y., Li, T., Zhao, P., Xu, J. W., et al. (2021). Myoinositol promotes lipid production and nutrients removal by microalga under molasses wastewater. Renew. Energ. 172, 327-335. doi: 10.1016/j.renene.2021. 03.051

Qu, D. H., and Miao, X. L. (2021). Carbon flow conversion induces alkali resistance and lipid accumulation under alkaline conditions based on transcriptome analysis in Chlorella sp. BLD. Chemosphere 265:129046. doi: 10.1016/j. chemosphere.2020.129046

Ramos, M. J., Fernandez, C. M., Casas, A., Rodriguez, L., and Perez, A. (2009). Influence of fatty acid composition of raw materials on biofuel properties. Bioresour. Technol. 100, 261-268. doi: 10.1016/j.biortech.2008.06.039

Riccioni, G. (2012). Marine carotenoids and oxidative stress. Mar. Drugs 10, 116-118. doi: $10.3390 / \mathrm{md} 10010116$

Ruban, A. V., Lavaud, J., Rousseau, B., Guglielmi, G., Horton, P., and Etienne, A. L. (2004). The super-excess energy dissipation in diatom algae: comparative analysis with higher plants. Photosynth. Res. 82, 165-175. doi: 10.1007/s11120004-1456-1

Sahin, M. S., Khazi, M. I., Demirel, Z., and Dalay, M. C. (2019). Variation in growth, fucoxanthin, fatty acids profile and lipid content of marine diatoms Nitzschia sp. and Nanofrustulum shiloi in response to nitrogen and iron. Biocatal. Agric. Biotechnol. 17, 390-398. doi: 10.1016/j.bcab.2018.1 2.023

Santos, A. M., Lamers, P. P., Janssen, M., and Wijffels, R. H. (2013). Biomass and lipid productivity of Neochloris oleoabundans under alkaline-saline conditions. Algal Res. 2, 204-211. doi: 10.1016/j.algal.2013.04.007

Sathasivam, R., and Ki, J. S. (2018). A review of the biological activities of microalgal carotenoids and their potential use in healthcare and cosmetic industries. Mar. Drugs 16:26. doi: 10.3390/md16010026

Shifrin, N. S., and Chisholm, S. W. (2010). Phytoplankton lipids: interspecific differences and effects of nitrate, silicate and light-dark cycles. J. Phycol. 17, 374-384. doi: 10.1111/j.1529-8817.1981.tb00865.x

Stansell, G. R., Gray, V. M., and Sym, S. D. (2012). Erratum to: microalgal fatty acid composition: implications for biofuel quality. J. Appl. Phycol. 24, 985-985. doi: 10.1007/s10811-012-9824-2

Sun, Z., Wang, X. F., and Liu, J. (2019). Screening of Isochrysis strains for simultaneous production of docosahexaenoic acid and fucoxanthin. Alagal Res. 41:101545. doi: 10.1016/j.algal.2019.101545 
Tan, L. J., Xu, W. J., He, X. L., and Wang, J. T. (2019). The feasibility of Fv/Fm on judging nutrient limitation of marine algae through indoor simulation and in situ experiment. Estuar. Coast. Shelfs 229:106411. doi: 10.1016/j.ecss.2019. 106411

Tanaka, T., Shnimizu, M., and Moriwaki, H. (2012). Cancer chemoprevention by carotenoids. Molecules 17, 3202-3242. doi: 10.3390/molecules 17033202

Vadlamani, A., Viamajala, S., Pendyala, B., and Varanasi, S. (2017). Cultivation of microalgae at extreme alkaline $\mathrm{pH}$ conditions: a novel approach for biofuel production. ACS. Sustain. Chem. Eng. 5, 7284-7294. doi: 10.1021/ acssuschemeng.7b01534

Wang, S., Said, I. H., Thorstenson, C., Thomsen, C., Ullrich, M. S., Kuhnert, N., et al. (2018a). Pilot-scale production of antibacterial substances by the marine diatom Phaeodactylum tricornutum Bohlin. Algal Res. 32, 113-120. doi: 10.1016/j.algal.2018.03.014

Wang, S., Verma, S. K., Said, I. H., Thomsen, L., Ullrich, M. S., and Kuhnert, N. (2018b). Changes in the fucoxanthin production and protein profiles in Cylindrotheca closterium in response to blue light-emitting diode light. Microb. Cell Fact. 17:110. doi: 10.1186/s12934-018-0957-0

Wang, W. J., Wang, G. C., Zhang, M., and Tseng, C. K. (2005). Isolation of fucoxanthin from the rhizoid of Laminaria japonica Aresch. J. Integr. Plant Biol. 47, 1009-1015. doi: 10.1111/j.1744-7909.2005.00054.X

Wang, X. J., Jin, G. Y., Wang, X. F., Ma, X. B., and Liu, Q. K. (2019). Separation, identification and assessing of potential application of a strain of Nitzschia sp. in Hamatai Lake. Hebei Fish. 11, 8-12+16. doi: 10.3969/j.issn.1004-6755.2019. 11.002

Wensel, P., Helms, G., Hiscox, B., Davis, W. C., Kirchhoff, H., Bule, M., et al. (2014). Isolation, characterization, and validation of oleaginous, multi-trophic, and haloalkaline-tolerant microalgae for two-stage cultivation. Algal Res. 4, 2-11. doi: 10.1016/j.algal.2013.12.005

Wu, H. L., Li, T., Dai, S. K., He, H., and Xiang, W. Z. (2016). A comparative analysis of fatty acid composition and fucoxanthin content in six Phaeodactylum tricornutum strains from diff erent origins. Chin. J. Oceanol. Limnol. 34, 391-398. doi: 10.1007/s00343-015-4325-1

Xia, S., Gao, B. Y., Fu, J. Q., Xiong, J. H., and Zhang, C. W. (2018). Production of fucoxanthin, chrysolaminarin, and eicosapentaenoic acid by Odontella aurita under different nitrogen supply regimes. J. Biosci. Bioeng. 126, 723-729. doi: 10.1016/j.jbiosc.2018.06.002

Xia, S., Wang, K., Wan, L. L., Li, A. F., Hu, Q., and Zhang, C. W. (2013). Production, characterization, and antioxidant activity of fucoxanthin from the marine diatom, Odontella aurita. Mar. Drugs 11, 2667-2681. doi: 10.3390/md11072667
Yang, Z. H., Zhao, Y., Liu, Z. Y., Liu, C. F., Hu, Z. P., and Hou, Y. Y. (2017). A mathematical model of neutral lipid content in terms of initial nitrogen concentration and validation in coelastrum sp HA-1 and application in Chlorella sorokiniana. Biomed. Res. Int. 2017:9253020. doi: 10.1155/2017/ 9253020

Yang, Z. K., Niu, Y. F., Ma, Y. H., Xue, J., Zhang, M. H., Yang, W. D., et al. (2013). Molecular and cellular mechanisms of neutral lipid accumulation in diatom following nitrogen deprivation. Biotechnol. Biofuels 6:67. doi: 10.1186/17546834-6-67

Zarekarizi, A., Hoffmann, L., and Burritt, D. (2019). Approaches for the sustainable production of fucoxanthin, a xanthophyll with potential health benefits. J. Appl. Phycol. 31, 281-299. doi: 10.1007/s10811-018-1558-3

Zeng, J., Zhang, Y. P., Ruan, J. P., Yang, Z. G., Wang, C. G., Hong, Z., et al. (2018). Protective effects of fucoxanthin and fucoxanthinol against tributyltininduced oxidative stress in HepG2 cells. Environ. Sci. Pollut. Res. 25, 5582-5589. doi: 10.1007/s11356-017-0661-3

Zeng, X. H., Danquah, M. K., Chen, X. D., and Lu, Y. H. (2011). Microalgae bioengineering: from CO2 fixation to biofuel production. Renew. Sust. Energ. Rev. 15, 3252-3260. doi: 10.1016/j.rser.2011.04.014

Zhang, C. W., Zmora, O., Kopel, R., and Richmond, A. (2001). An industrialsize flat plate glass reactor for mass production of Nannochloropsis $\mathrm{sp}$ (Eustigmatophyceae). Aquaculture 195, 35-49. doi: 10.1016/S0044-8486(00) 00533-0

Conflict of Interest: The authors declare that the research was conducted in the absence of any commercial or financial relationships that could be construed as a potential conflict of interest.

Publisher's Note: All claims expressed in this article are solely those of the authors and do not necessarily represent those of their affiliated organizations, or those of the publisher, the editors and the reviewers. Any product that may be evaluated in this article, or claim that may be made by its manufacturer, is not guaranteed or endorsed by the publisher.

Copyright (C) 2022 Cao, Shen, Wang, Zhu, Pan and Li. This is an open-access article distributed under the terms of the Creative Commons Attribution License (CC BY). The use, distribution or reproduction in other forums is permitted, provided the original author(s) and the copyright owner(s) are credited and that the original publication in this journal is cited, in accordance with accepted academic practice. No use, distribution or reproduction is permitted which does not comply with these terms. 